\section{Pistol Bullets: Not Fired But Ingested by a Patient of Borderline Personality Disorder}

\section{Sir,}

Emotionally unstable personality has been a common disorder in all parts of the world. ${ }^{1}$ It is usually predominant in young females. Patients with this type of personality disorder or trait have the history of self-harm for various reasons. Common modes of self-harm include ingestion of benzodiazepines or other substances. Slashing of wrists and other body parts also stands as a common mode of self-harm among the borderline personality people. ${ }^{2}$

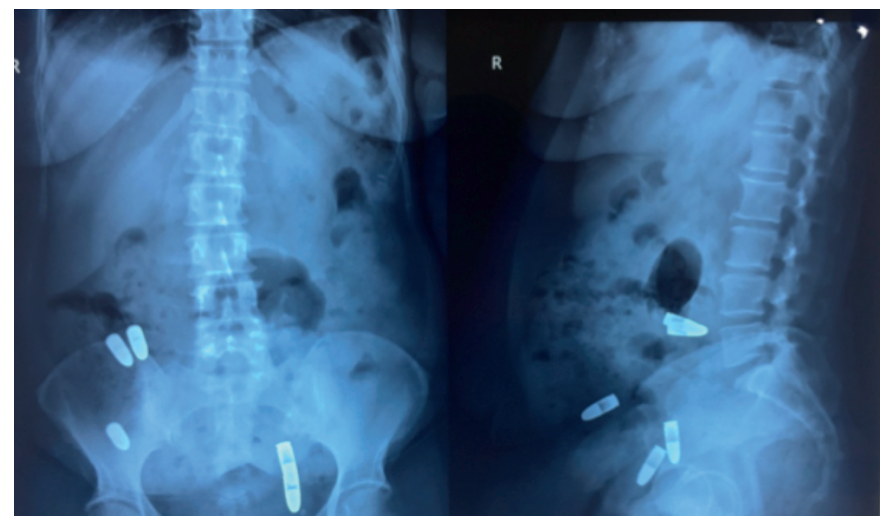

Figure 1: Abdominal X-ray showing pistol bullets in the lower abdomen on antero-posteriorand lateral views.

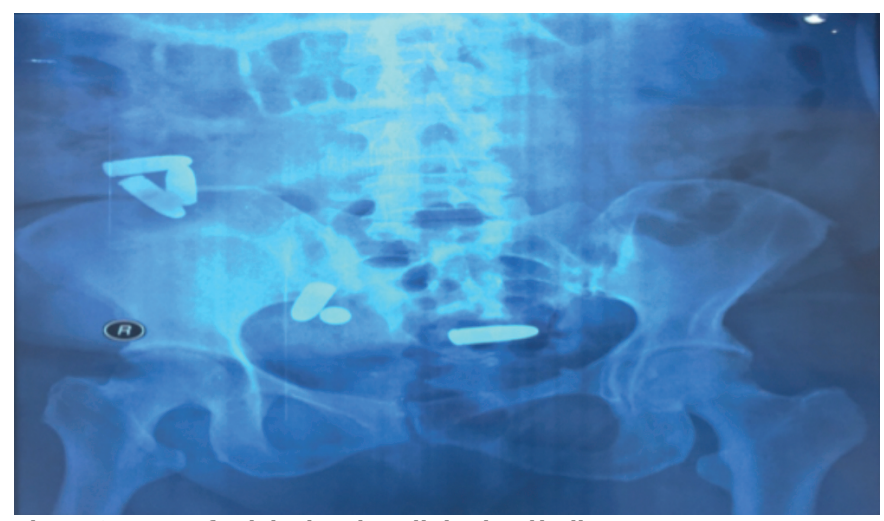

Figure 2: X-ray of pelvis showing all six pistol bullets.

In our case, a 58 years old housewife was brought by her husband on account of an act of deliberate self-harm in which she had impulsively ingested six bullets taken from her husband's pistol with the intent to die. She did it after a conflict with her youngest daughter. She also took overdose of 4-10 tablets of clonazepam and metformin/vidagliptin followed by profuse vomiting and loose stools. Her X-ray abdomen and pelvis confirmed presence of six bullets (Figures 1 and 2 ). She was conservatively managed by medical specialist and was kept on laxatives. She was also being followed by surgical specialist, who later did not suggest any surgical intervention as she had passed all six bullets in stools within the next five days. She had disturbed sleep, mood instability, argumentative behaviour and irritability for a week. She had been under irregular psychiatric care for the last 20 years for mood instability, interpersonal difficulties, and multiple attempts of drug overdose. Patient lived separated from biological parents in her early life. Her marital life remained strained. She had three daughters but they always stood by their father against her adding to her agony. Pre-morbidly, she had impulsive personality traits with low stress tolerance. She was diabetic for past twelve years. However, there was no history of mania, substance abuse, violence or headinjury. She was middle aged lady of average height and obese built, was unkempt, uncooperative, irritable and violent. She was neither making eye contact nor establishing rapport easily. Her speech was relevant and coherent. Her mood was irritable with appropriate affect. She was preoccupied by her psycho-social stressors and harboured fleeting ideas of suicide but no psychotic features. She had intact cognitive functions with preserved insight. She was managed on tablet Sodium Valproate, tablet Escitalopram and tablet Zolpidem. Patient's psychological sessions were conducted by psychologists, which included guided self-help and cognitive behavioural therapies. Patient was advised to keep contact through an emergency contact number in case of need.

Multiple cases of sharp or dangerous objects ingestion by borderline patients have been reported including razors, pens, pencils and even glass pieces. Not only oral ingestion has been reported, but also anal and vaginal insertion has been reported by the patients. ${ }^{3}$ Our case was different in the sense that age of the patient was more than all the cases of these acts reported previously and nobody ingested the bullets of pistols. This highlights the fact that patients of personality disorders should be screened throughout their life for ideas of self-harm and that too from the objects which have been unusual for this purpose.

\section{CONFLICT OF INTEREST:}

Authors declared no conflict of interest.

\section{AUTHORS' CONTRIBUTION:}

SK: Data collection, manuscript writing.

UZ: Manuscriptwriting.

RQ: Patient management, final approval, concept and design. NS: Critical revision.

\section{REFERENCES}

1. Guilé JM, Boissel L, Alaux-Cantin S, de La Rivière SG. Borderline personality disorder in adolescents: prevalence, diagnosis, and treatment strategies. Adolesc Health Med Ther 2018; 9:199-210.

2. Goodman M, Tomas IA, Temes CM, Fitzmaurice GM, Aguirre BA, Zanarini MC. Suicide attempts and self-injurious behaviours in adolescent and adult patients with borderline 
personality disorder. Personal Ment Health 2017; 11(3): 157-63.

3. Gitlin DF, Caplan JP, Rogers MP, Avni-Barron O, Braun I, Barsky AJ. Foreign-body ingestion in patients with personality disorders. Psychosomatics 2007; 48(2):162-6

Sana Khan ${ }^{1}$, Usama bin Zubair ${ }^{2}$, Rashid Qayyum ${ }^{4}$ and Nomita Sohail

${ }^{1}$ Armed Forces Institute of Mental Health, Rawalpindi, Pakistan ${ }^{2}$ The Mater Misericordiae University Hospital, Dublin, Ireland
${ }^{3}$ Department of Psychiatry, Fazaia Medical College, PAF Hospital, Islamabad, Pakistan

Correspondence to: Dr. Sana Khan, Department of Psychiatry, Armed Forces Institute of Mental Health, Rawalpindi, Pakistan

E-mail: waved08@gmail.com

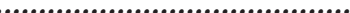

Received: July 12, 2019; Revised: July 13, 2019; Accepted: October 24, 2019

DOI: https://doi.org/10.29271/jcpsp.2020.06.671 